\title{
FORQUETA: A MEMÓRIA DOS ESQUECIDOS
}

\author{
ROSA, Nicole \\ Universidade de Caxias do Sul - UCS, e-mail: nrosal @ucs.br \\ BALDISSERA, Doris \\ Universidade de Caxias do Sul - UCS, e-mail: dbaldis1 @ucs.br
}

\begin{abstract}
RESUMO
O presente artigo apresenta o projeto Foqueta: a memória dos esquecidos, que foi premiado com a segunda colocação no concurso universitário Urban21, na edição de 2018. A proposta traz soluções para requalificar o distrito levando em consideração seus aspectos culturais, patrimoniais, de mobilidade e equipamentos urbanos, bem como recuperar a relação da comunidade com os espaços abertos. Outro fator muito relevante na proposta é a qualificação do roteiro turístico do Vale Trentino, visando o reconhecimento do distrito como um grande produtor de vinhas e uvas, além de abrigar a primeira cooperativa de vitivinícola da América Latina. Para demostrar a sustentabilidade da proposta são feitas prospecções com a delimitação de 10, 20 e 50 anos, demonstrando que as ações se tornam viáveis e podem qualificar o distrito a curto, médio e longo prazo.
\end{abstract}

Palavras-chave: Urban21, Forqueta, Urbanismo, Requalificação, Mobilidade.

\begin{abstract}
This article presents the Foqueta project: the memory of the forgotten, which was awarded the second place in the competition Urban21, in the edition of 2018. The proposal brings solutions to requalify the district taking into account its cultural, patrimonial, mobility and urban equipment, as well as recovering the relationship of the community with open spaces. Another very important factor in the proposal is the qualification of the tourist route of the Trentino Valley, aiming at the recognition of the district as a major producer of vineyards and grapes, in addition to housing the first wine cooperative in Latin America. In order to demonstrate the sustainability of the proposal, prospects with the delimitation of 10,20 and 50 years are made, demonstrating that the actions become viable and can qualify the district in the short, medium and long term.
\end{abstract}

Keywords: Urban21, Forqueta, Urbanism, Requalification, Mobility.

\section{INTRODUÇÃO}

O artigo trata do projeto intitulado "Forqueta: a memória dos esquecidos", que foi premiado com a segunda colocação, no concurso universitário Urban21, na edição de 2018.

Forqueta é um distrito do município de Caxias do Sul, no Rio Grande do Sul, localizado a $15 \mathrm{~km}$ da área central da cidade, contando com aproximadamente 3.700 habitantes (IBGE, 2010). Foi uma das primeiras áreas ocupadas pelos imigrantes italianos, ao chegarem na Encosta Superior do Nordeste, sendo hoje a maior produtora de vinhos de Caxias do Sul.

ROSA, N.; BALDISSERA, D. Forqueta: a memória dos esquecidos. In: SIMPÓSIO BRASILEIRO DE QUALIDADE DO PROJETO NO AMBIENTE CONSTRUÍDO, 6., 2019, Uberlândia. Anais... Uberlândia: PPGAU/FAUeD/UFU, 2019. p. 1237-1250. DOI https://doi.org/10.14393/sbqp19113. 
A proposta do projeto premiado buscou a qualificação do centro do distrito, com o reuso das edificações histórias, equipamentos e mobiliário urbanos adequados que valorizem essa centralidade, implantação de uma praça e reestruturação do roteiro turístico do Vale Trentino, onde se encontram as vinícolas de produção local.

Foi buscado demonstrar a viabilidade do projeto e os benefícios que o distrito alcançará, pois, sua economia foi desestabilizada com a retirada do pedágio da rodovia RS-122, lindeira ao distrito, o que levou a perda do caráter de local de passagem alternativo acarretando em seu "esquecimento". Esse fenômeno afeta a venda de produtos locais e a vida da comunidade, que com a visão do projeto, teria um atrativo para potencializar seu crescimento, não apenas como espaço de passagem, mas como um centro turístico reconhecido pelo seu real valor histórico para a região.

\section{O CONCURSO}

O Urban21 é um concurso em nível nacional e tem por princípio incentivar e motivar os universitários, através do desenvolvimento de propostas de intervenções urbanística, que venham a qualificar a vida das pessoas de forma simples e real.

O planejamento urbano passa a ser uma ferramenta fundamental para a promoção da vitalidade urbana e consciência ambiental nos espaços densificados, bem como na conscientização dos novos profissionais a pensarem ações que possam atribuir qualidades aos espaços urbanos e ao mesmo tempo repensar os espaços e recriar a promoção cultural e social de diversidade que apenas os centros urbanos podem nos conceder.

O concurso, que no ano de 2018 teve sua quarta edição, foi promovido pela revista PROJETO e patrocinado pela empresa Alphaville Urbanismo, teve por objetivo difundir o urbanismo sustentável, garantindo a qualidade do projeto e ao mesmo tempo pensando na viabilidade de execução do mesmo.

Com a chamada "O urbanismo é para todos", a edição de 2018, teve premiado como segundo lugar o trabalho intitulado Forqueta: A memória dos esquecidos, elaborado pelos acadêmicos do curso de Arquitetura e Urbanismo da Universidade de Caxias do SUl - UCS, Bruno Guilherme Fabro, Bruno Gallina, Caroline Garaffa, Gessica Tonin, Guilherme Conte Rodrigues, Guilherme Jaskulski Oliveira, Juliana Tomazi Consenso e Thaise Zattera Marchesini, orientados pelas professoras Doris Baldissera e Nicole Rosa.

\section{O PROJETO}

\subsection{Inserção}

Localizado na região nordeste o Estado do Rio Grande do Sul, Região Metropolitana da Serra Gaúcha, na cidade de Caxias do Sul, o distrito de Forqueta, formado por colônias de imigração italiana, ainda apresenta em sua área rural características fortes dessa colonização.

A localidade se consolidou como um importante eixo estruturador de mobilidade entre as cidades de Caxias do Sul e Farroupilha, pois a "Estrada Velha", que atravessa Forqueta era utilizada inicialmente como estrutura viária para o assentamento agrícola colonial. Posteriormente com a implantação do 
pedágio na rodovia RS-122, passou a servir de rota alternativa para desviar tal estrutura, o que trouxe um intenso trafego veicular que culminou com a consolidação de alguns comércios de produtos locais. Com a desativação do pedágio da rodovia principal, a estrada voltou a ser apenas de uso local e a suas funções comerciais e de serviços, esquecidas pelos usuários constantes.

\subsection{Conceitos e Objetivos}

Forqueta é reconhecida principalmente pelas suas paisagens culturais, naturais e edificadas. Esses atributos determinam o Genius Loci, ou "espírito do lugar" (BAKER, 1991), que é a representação material e cultural de uma população que se dá através da mistura das tradições passadas, reproduzidas no cotidiano, e a inclusão de elementos urbanos, que antes não pertenciam ao lugar, mas que passam a compor o panorama da identidade local. Esse fenômeno foi intensificado em Forqueta com a implantação do sistema ferroviário que conta com uma estação (gare) de embarque e desembarque no centro do distrito, o que foi determinante para a estruturação do território.

Os centros de atividades nascem em distritos vivos e diversificados, do mesmo modo como surgem, em escala menor, em parques, e tais centros favorecem a identidade do distrito se também contiverem um ponto de referência que represente simbolicamente o lugar $e$, em certo sentido, o distrito (JACOBS, 2000, p. 142).

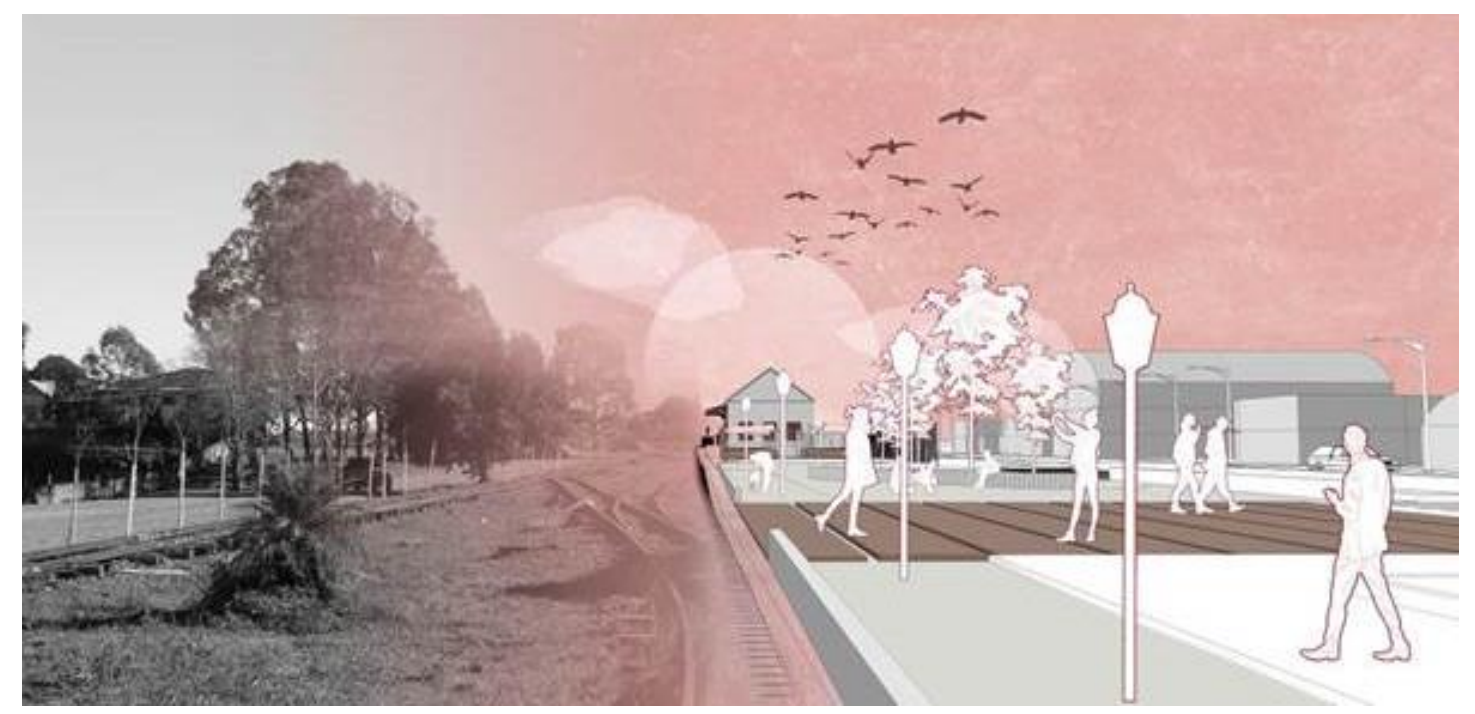

Figura 1 - Fotomontagem de Forqueta com a praça da Gare Fonte: Autoras (2018)

O projeto tem por objetivo resgatar o centro histórico e a criação de múltiplos caminhos que expressem a memória local que se reflete nas atividades turísticas e nos espaços de lazer, estabelecendo um sentido de coletividade ao distrito, relacionando o patrimônio edificado, as paisagens naturais e cultivadas, pois o conjunto edificado de Forqueta é a expressão da bagagem cultural do lugar.

Por ser um símbolo físico que resiste ao tempo e às gerações, os edifícios representam não apenas um abrigo, mas também podem servir de registro para as manifestações culturais de uma região, podendo evidenciar através de sua forma, tecnologia ou ornamentos, marcas de uma cultura ou a mistura 
de várias, servindo de palco de memória para as gerações futuras (VICTUR, 2007, p. 73).

Além disso, as proposições trazem um novo olhar para locais pouco lembrados, consequência muitas vezes do investimento em as novas estruturas projetadas em áreas de expansão urbana ou pela falta de políticas públicas. Essa forma de planejamento urbano apresenta métodos positivos para rearranjar percursos a partir de pré-existências, buscando qualificar esses centros existentes e consolidados.

\subsection{Proposta}

A proposta está baseada em três grandes pilares, a requalificação do centro de Forqueta, com a reestruturação da linha férrea, que atravessa o distrito, como uma praça de centralização das atividades comerciais e culturais. A destinação de novos usos para as edificações históricas do centro, fazendo com que as mesmas sejam recuperadas e reocupadas, trazendo mais vitalidade urbana e atrativo turístico com finalidade de potencializar a economia local. Por fim, a estruturação de um roteiro turístico que englobe o Vale do Trentino, que apesar de estar implantado de direito não se efetua de fato, tendo apenas vinícolas com o viés produtivo e de distribuição local. Na proposta ela passa a ser um centro atrator de atividades de lazer, comércio e cultura para Forqueta e região.

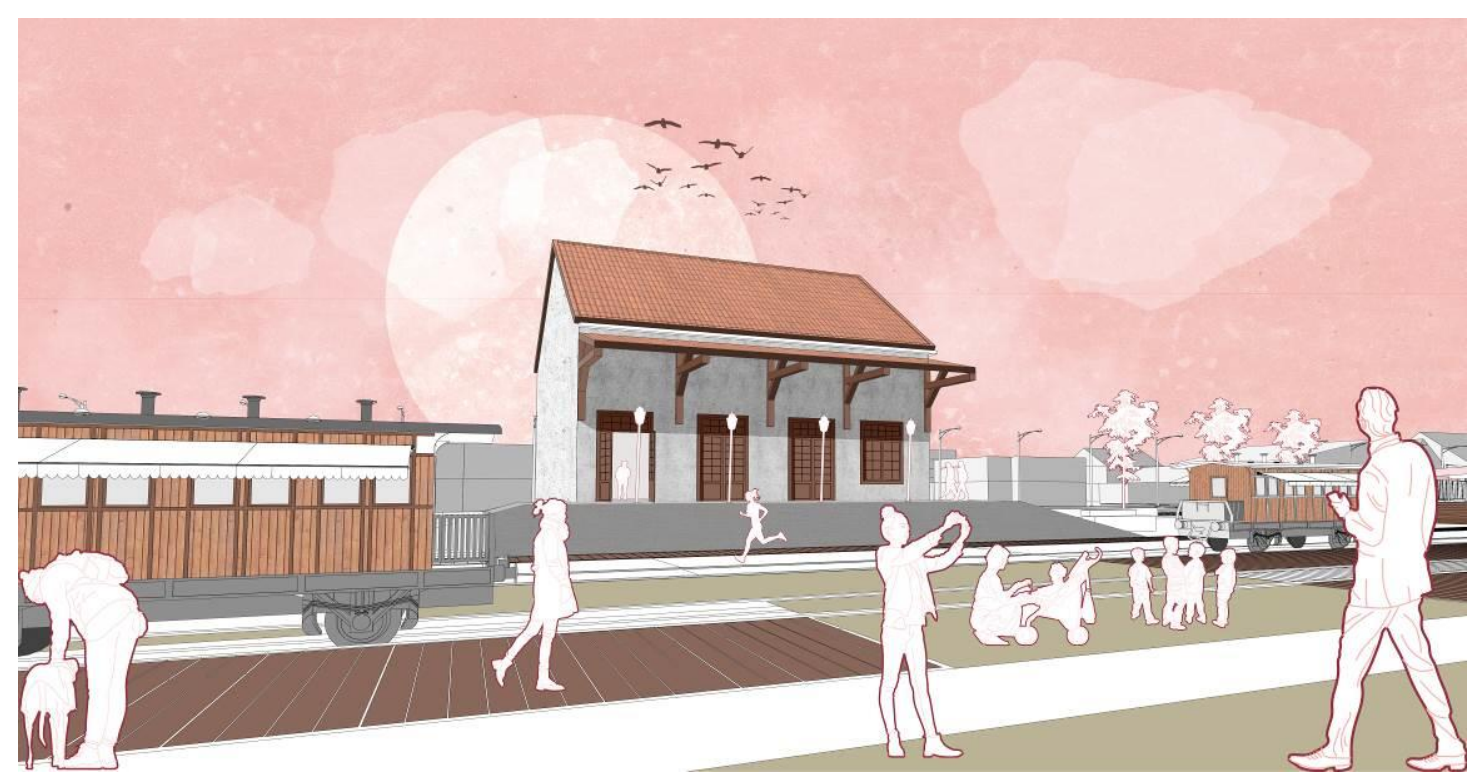

Figura 2 - Praça da Gare -

Fonte: Autoras (2018)

Para que se pudesse estabelecer as bases de intervenções e atuação no distrito, foi feito um diagnóstico da área que receberia as proposições, com isso se estabeleceu o seguinte recorte de intervenção urbanística: 1. A área central, ativamente usada pela população para atividades sociais e comerciais, de fácil acesso ao transporte público, com maior concentração de moradias e com grande potencial para abrigar um ambiente que estimule a circulação e a vitalidade do espaço público; 2. O roteiro cultural do Vale do Trentino foi visto como um grande polo de turismo a ser valorizado e qualificado, oferecendo visitação nas vinícolas. O deslocamento dos visitantes 
ocorreria em veículos automotores ou através da rota cicloviária que conta com infraestrutura de apoio.

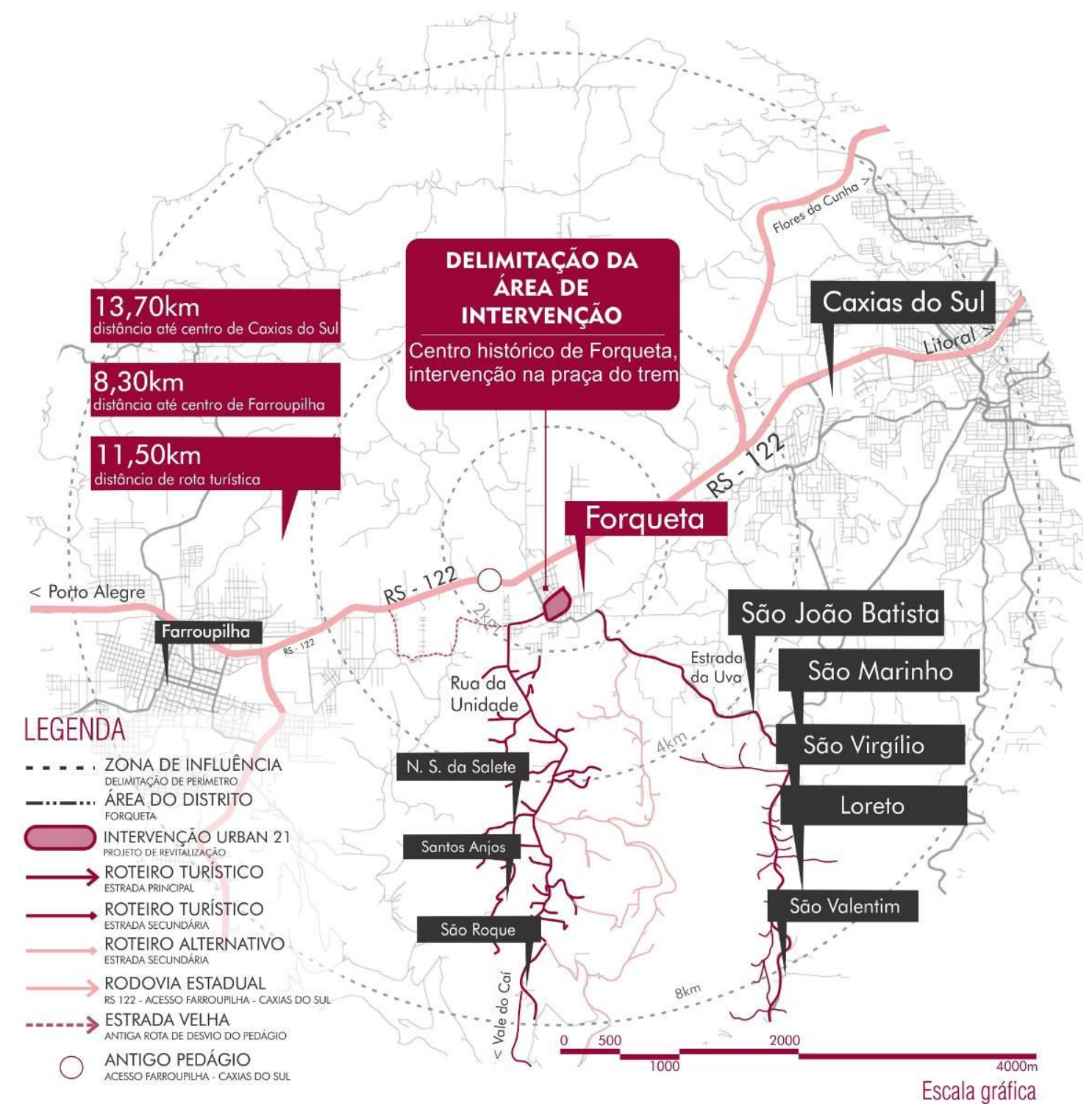

Figura 3 - Mapa da área de intervenção -

Fonte: Autoras (2018)

Como intenção de atrativo e valorização da comunidade local de Forqueta, foi proposta para a área central a qualificação das vias que priorizam o bemestar do pedestre, a inserção de ciclofaixas, reciclagem dos usos de edifícios subutilizados e de outros que são parte da história patrimonial do distrito, e a proposição de novos espaços que incentivem as atividades de turismo e de consumo existentes. Essa requalificação contribuirá economicamente para o desenvolvimento local e posteriormente, atrairá novos públicos para o roteiro turístico do Vale Trentino, possibilitando a sustentabilidade e viabilidade dessa proposta.

O conjunto edificado pontuado na área central de intervenção define o lugar que caracterizou Forqueta como o primeiro centro cooperativo de vitivinícola da América Latina. Esses edifícios carregam a história e revelam a produção diária do que foi a comunidade no auge do estabelecimento do ciclo da uva 
e do vinho, produção industrial e enriquecimento de outras atividades que sustentavam essa comunidade. "A paisagem urbana é viva graças ao seu enorme acervo de pequenos elementos" (JACOBS, 2000, p.162).

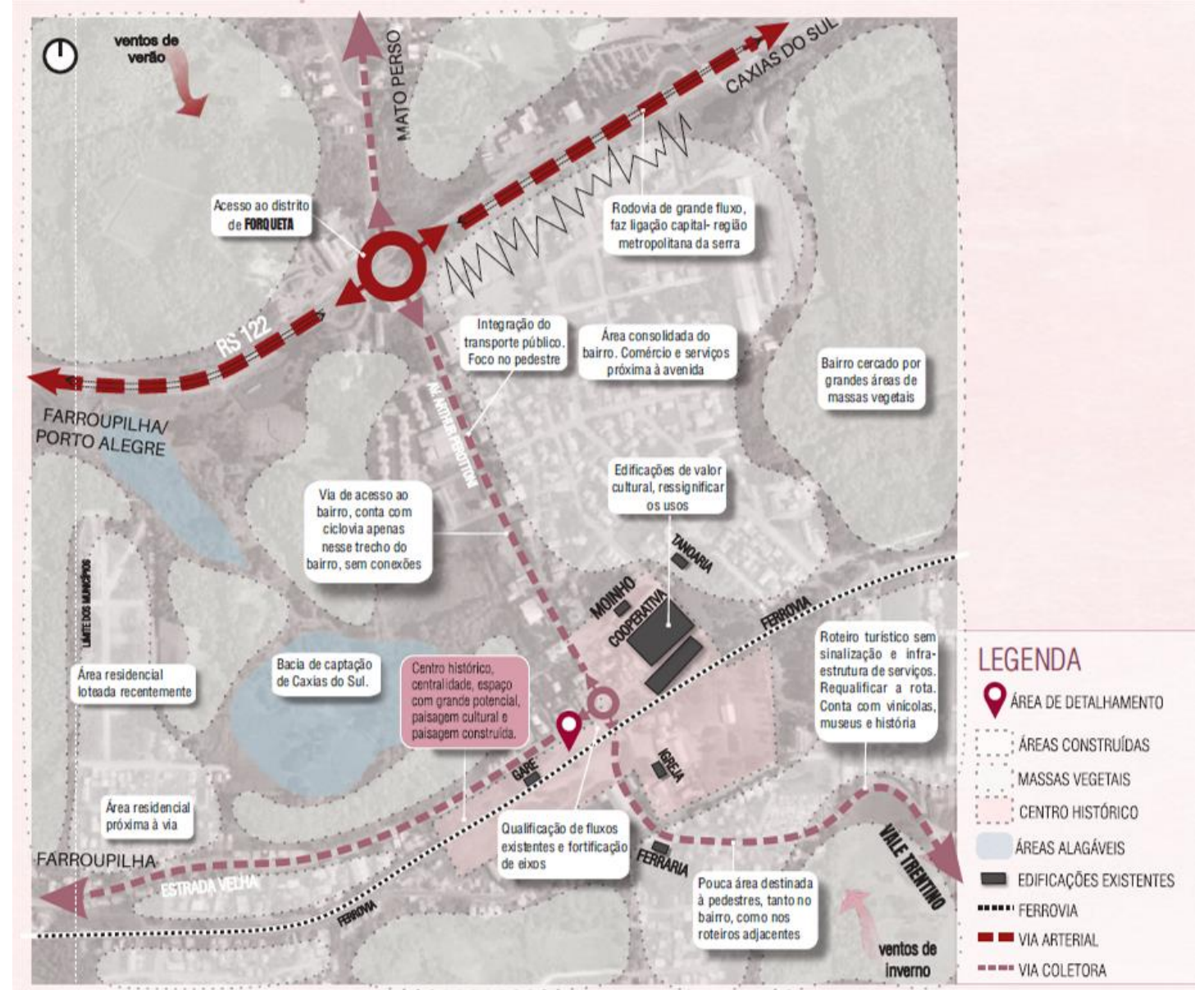

Figura 4 - Mapa síntese de análise -

Fonte: Autoras (2018)

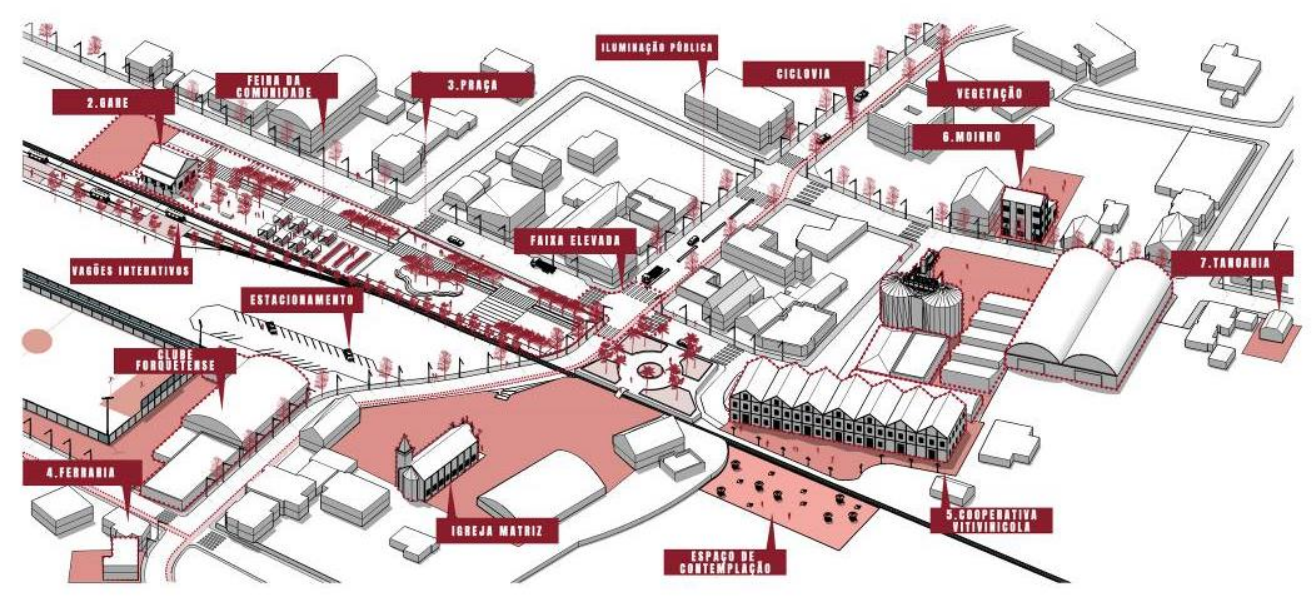

Figura 5 - Mapa da área central de Forqueta Fonte: Autoras (2018)

A tanoaria era responsável pela fabricação das pipas onde era armazenado o vinho; o moinho atuava na produção de farinha para a fabricação de massas e pães que abasteciam e sustentavam os trabalhadores; a ferraria servia 
como um apoio para a fabricação das ferramentas para manutenção dos trilhos do trem, e também de utensílios, carroças e o que mais fosse feito nesse material; a Gare, servia como uma "estação", ponto de chegada e partida para quem buscava uma nova vida.

Dentro do conceito de comunidade e vitalidade, cada uma das edificações ganhou um novo uso e os espaços intraurbanos foram contemplados com atividades para a comunidade, bem como hortas comutarias, a praça da Gare e vagões culturais.

A Cooperativa vitivinícola (primeira da América Latina), hoje abriga o museu do vinho, na proposta além da qualificação do uso atual, ganha espaços de degustação, comercialização, lazer e consumo local.

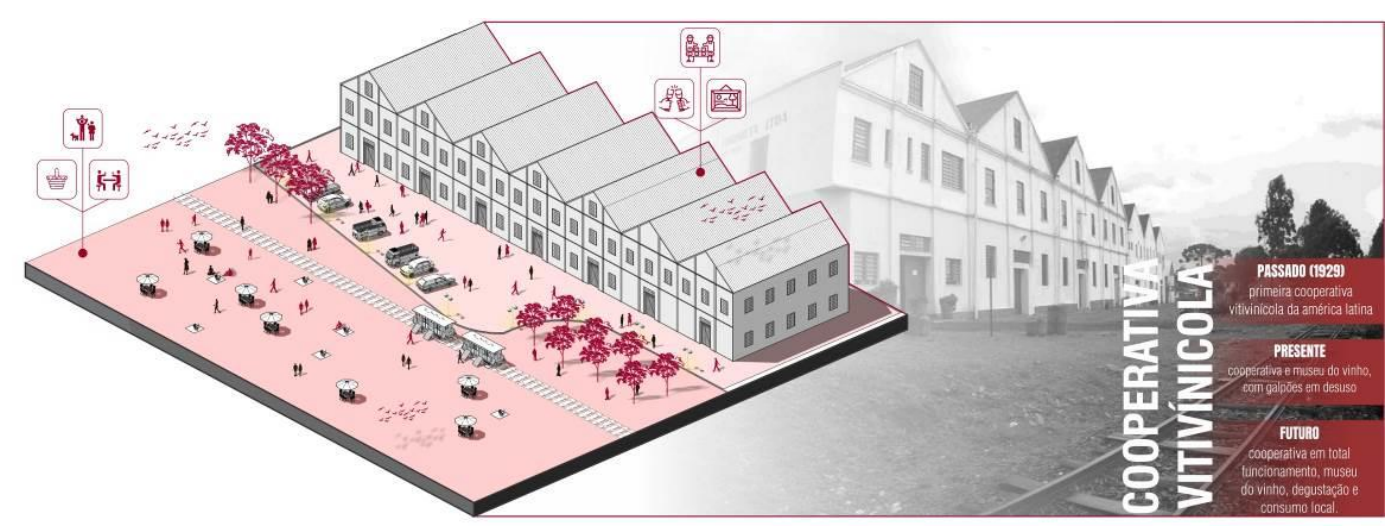

Figura 6 - Cooperativa Vitivinícola -

Fonte: Autoras (2018)

O moinho outrora utilizado na produção de massas e pães comercializados localmente se encontra desocupado e em estado de degradação. Na proposta recebe destaque, abrigando uma pousada para atender a demanda turística.

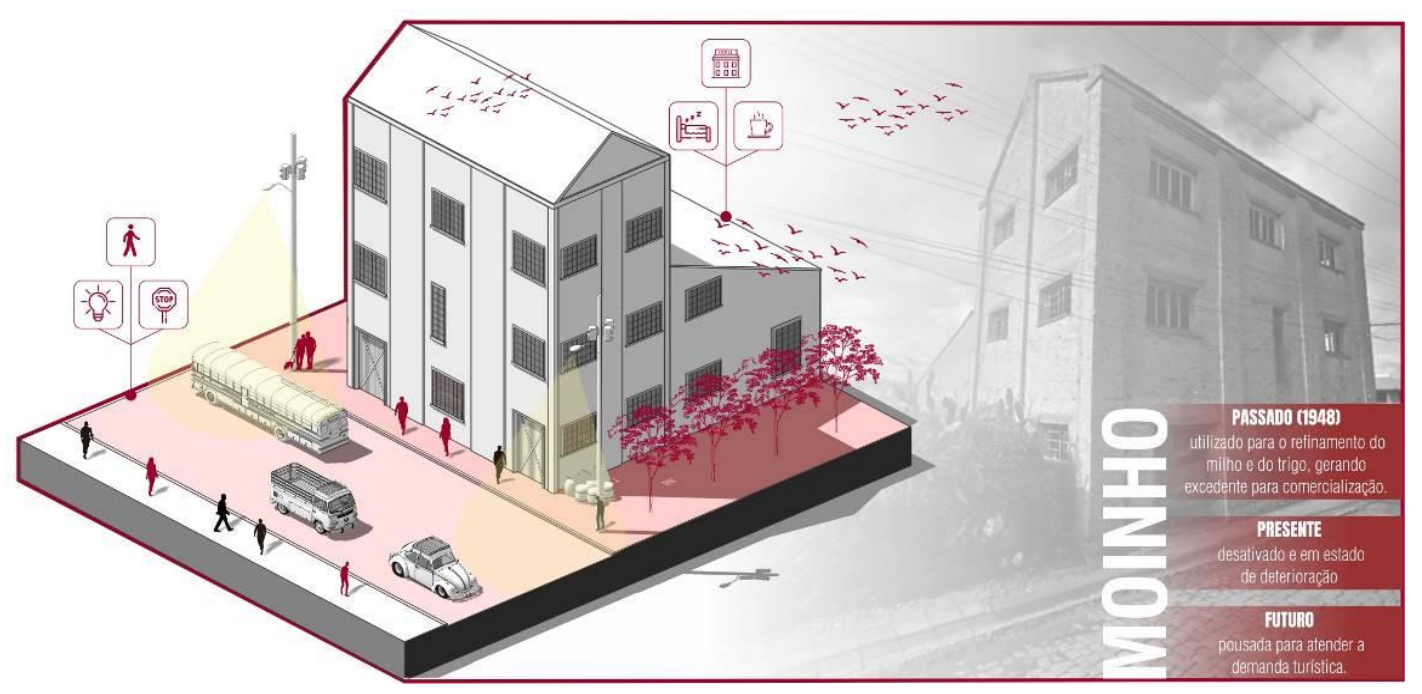

Figura 7 - Moinho -

Fonte: Autoras (2018)

A ferraria que produzia ferramentas para a manutenção da ferrovia e demais infraestruturas locais, se encontra desativada e em estado de deterioração. 
Esse edifício abrigará um espaço gastronômico para atender ao complexo criado.

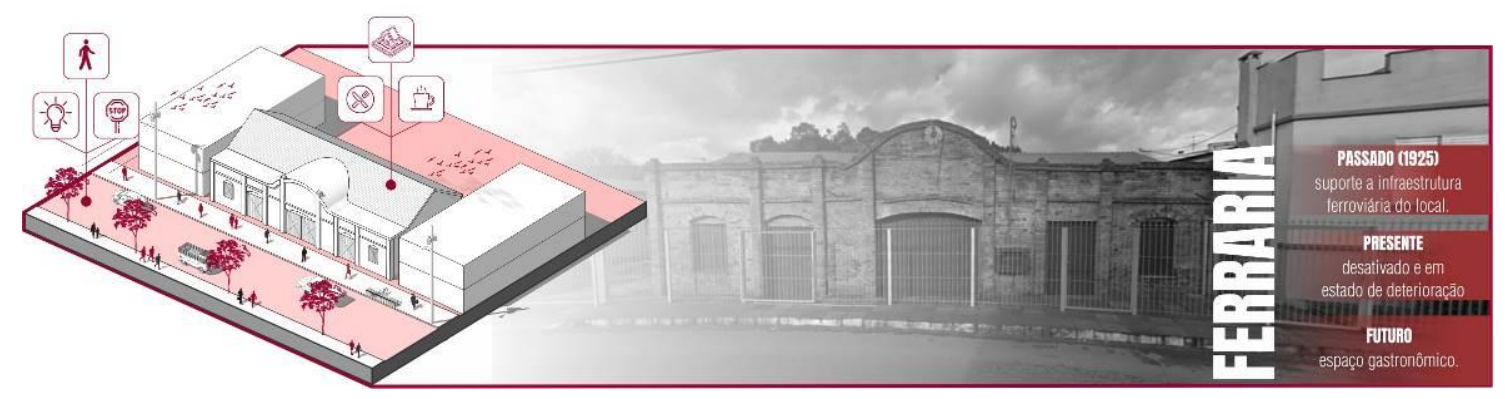

Figura 8 - Ferraria -

Fonte: Autoras (2018)

A tanoaria, onde eram produzidos os barris para armazenar o vinho, como os demais edifícios se encontra desativada. Na proposta abrigará um espaço que recupere o seu uso original sendo destinada as oficinas tanoeiras.

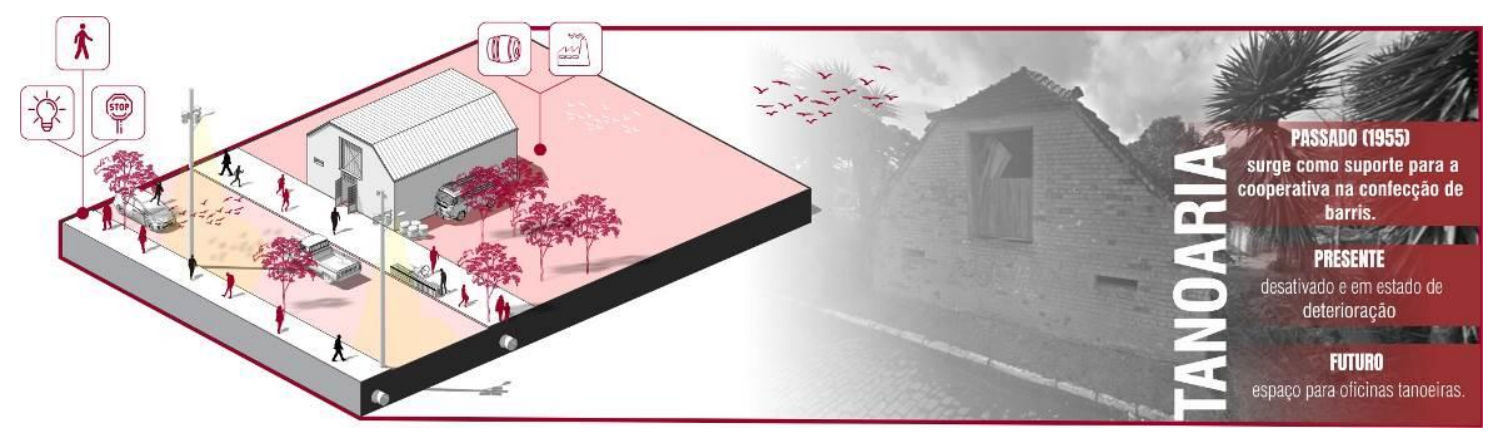

Figura 9 - Tanoaria -

Fonte: Autoras (2018)

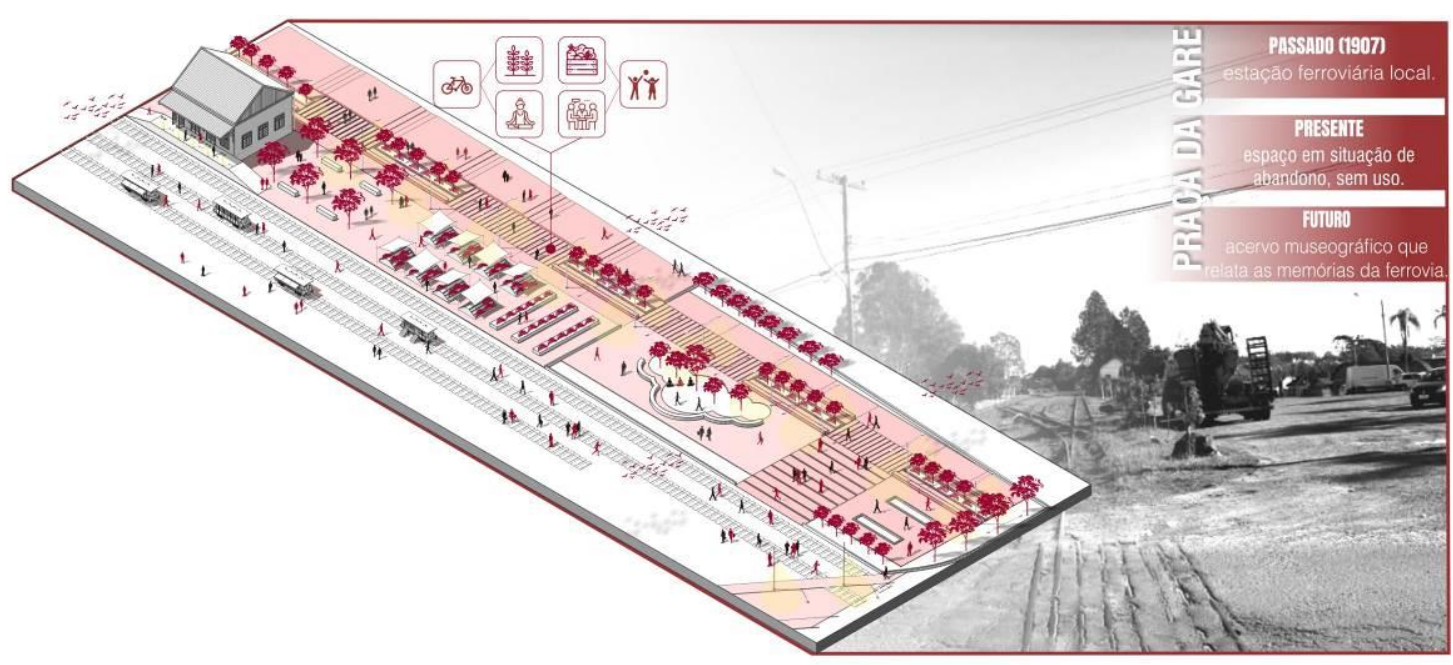

Figura 10 - Praça da Gare -

Fonte: Autoras (2018)

A área da antiga Gare tem papel fundamental no projeto de intervenção urbanística, servindo como explanada para uma praça que concentra as atividades sociais e culturais do local. Nesse espaço público os "vagões culturais" servirão de apoio abrigando oficinas, apresentações de música e dança, cinema e biblioteca. 
A praça é um dos principais espaços dentro da construção da estrutura urbana, tem um papel de orientação dentro da cidade, lugar de contato, de trocas e sociabilidade. A praça é um limite, mas também é uma costura e abriga as atividades de um grupo e revela com clareza a identidade que isso a confere (LYNCH, 1997, p. 52).
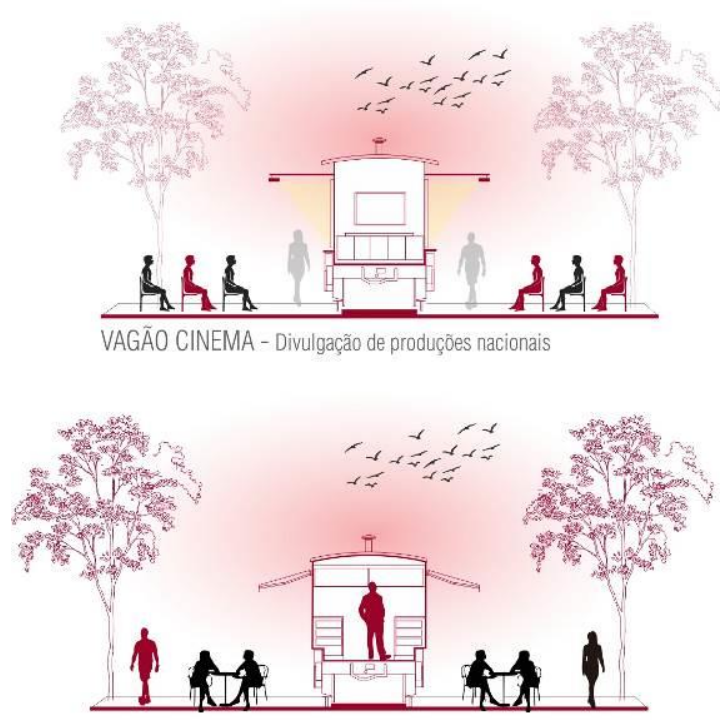

VAGÃOO BIBLIOTECA - Conta com acervo histórico/cultural voltado a região
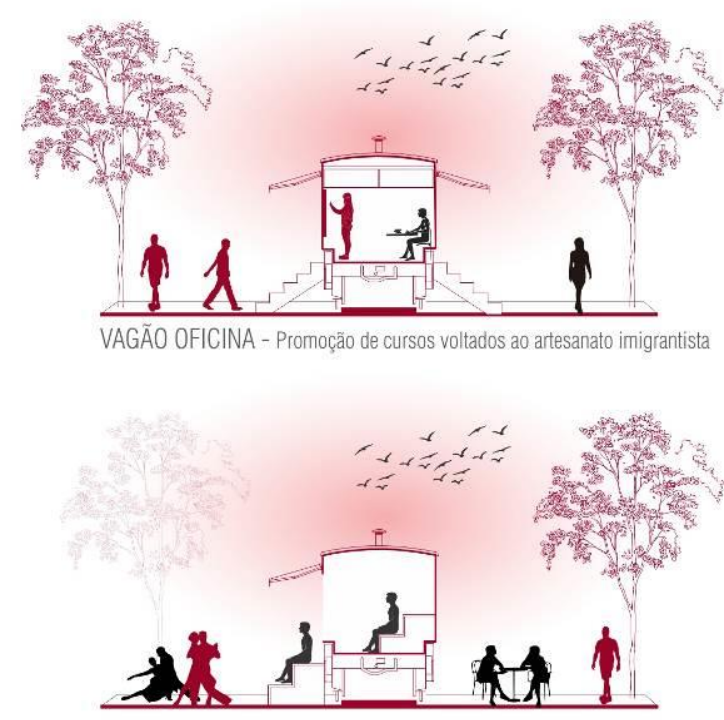

VAGÃO MÚSICA E DANÇA - Apresentação de grupos locais

Figura 11 - Vagões Culturais Fonte: Autoras (2018)

A horta urbana é um reflexo do que hoje Forqueta tem como apropriação do espaço e manutenção do espírito de comunidade, o projeto a traz para próximo da praça, mais conectada com as atividades urbanas e principalmente com seus usuários.

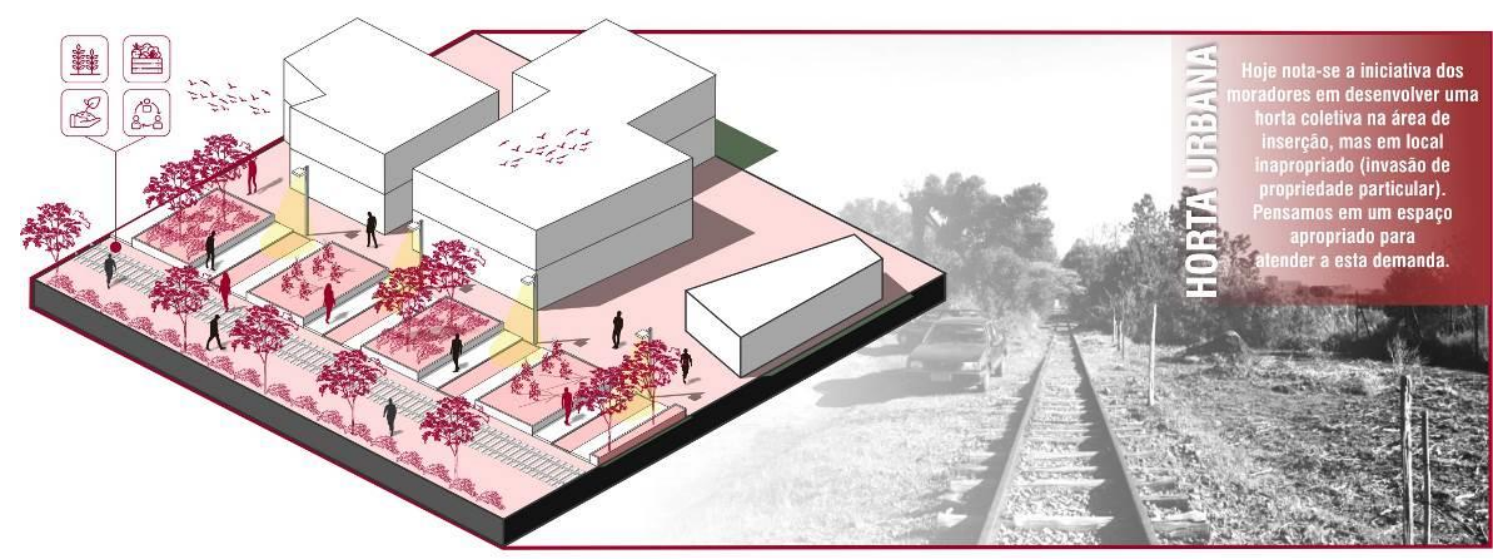

Figura 12 - Hortas Urbanas .

Fonte: Autoras (2018)

O tratamento ao longo da rua da Unidade (no Vale Trentino), foi feito para facilitar a coletividade do território, buscando facilitar as relações humanas e culturais, trazendo para Forqueta um caráter de acolhimento aos usuários. 


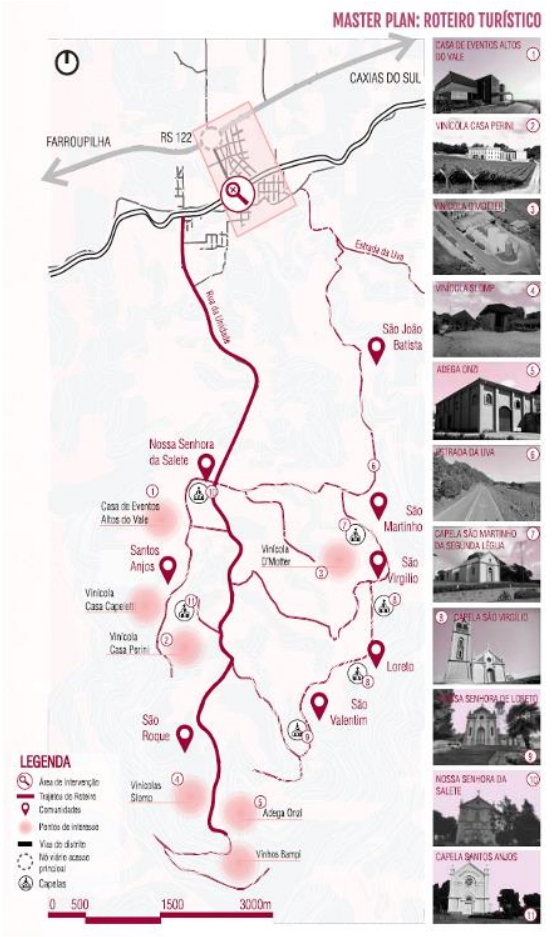

Figura 13 - Roteiro do Vale Trentino Fonte: Autoras (2018)

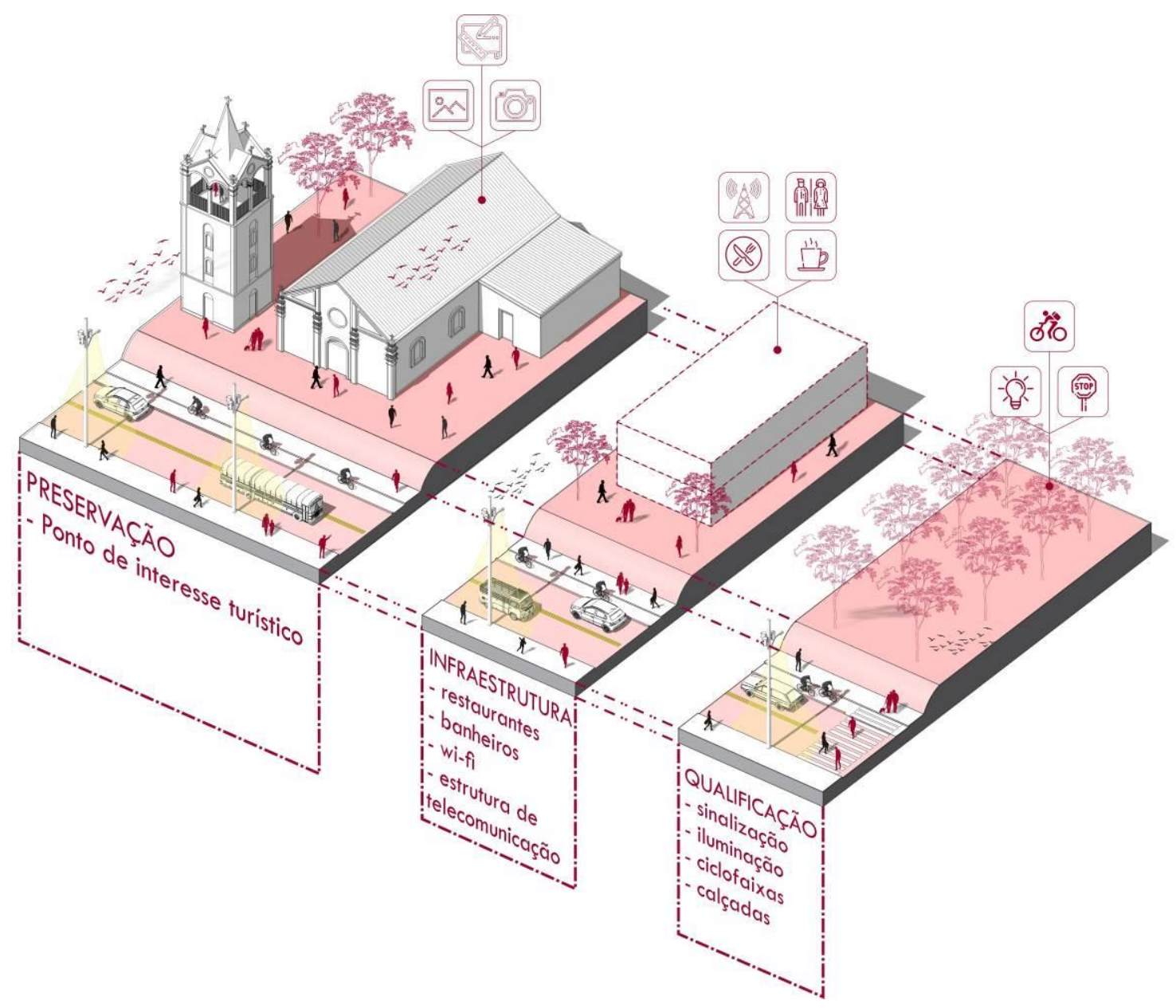

Figura 14 - Equipamentos urbanos no roteiro do Vale Trentino Fonte: Autoras (2018) 
As estratégias adotadas basearam-se na compreensão das forças e oportunidades para a qualificação do lugar, assim possibilitando a identificação e valorização do patrimônio, implantação de equipamentos estruturadores como pousadas, restaurantes, centros socioculturais, banheiros e de infraestrutura de comunicação e espaço para comercialização dos produtos fabricados na região.

Um dos fatores fundamentais para a aceitação e implementação do projeto é a conscientização da população local e sua qualificação para o acolhimento ao turista, pois será necessária a compreensão da potencialidade que as características de espírito do lugar, ali presentes e agora fortalecidas, terá na atração do turismo e consequentemente na valorização da cultura e economia locais.

\subsection{Mobilidade Urbana}

A mobilidade urbana é um desafio cada vez mais presente em intervenções urbanísticas da atualidade, mas Forqueta apresenta uma peculiaridade que é o fato de sempre ter sido uma rota de conexão, por vezes alternativa, entre Caxias do Sul e Farroupilha, mas também uma ligação entre o Vale Trentino e o escoamento da produção de vinhos em direção a Porto Alegre, capital do Estado.

As rotas que atravessam o distrito têm sua origem com o caminho dos tropeiros que conduzia o gado para o resto do país e cruzava o local, a passagem dos imigrantes alemães em direção a região das hortênsias e em seguida 0 estabelecimento de uma colônia italiana com a chegada da via férrea e a criação da estrada velha, que dava acesso as propriedades rurais. Pôr fim a construção da RS-122, importante rodovia, que liga Caxias do Sul a Farroupilha e que é paralela a Forqueta.

Uma das características marcantes do local é o modo como essas rotas definiram e auxiliaram a estabelecer a identidade do distrito. Em todas as suas fases, essas conexões estabeleceram relações importantes com a localidade, mas o que gerou maior impacto acabou sendo a difusão do "urbanismo rodoviário", onde o aumento da velocidade transferiu os viajantes da "estrada velha" para a RS-122, o que fez com que o distrito acabasse sendo esquecido para esses.

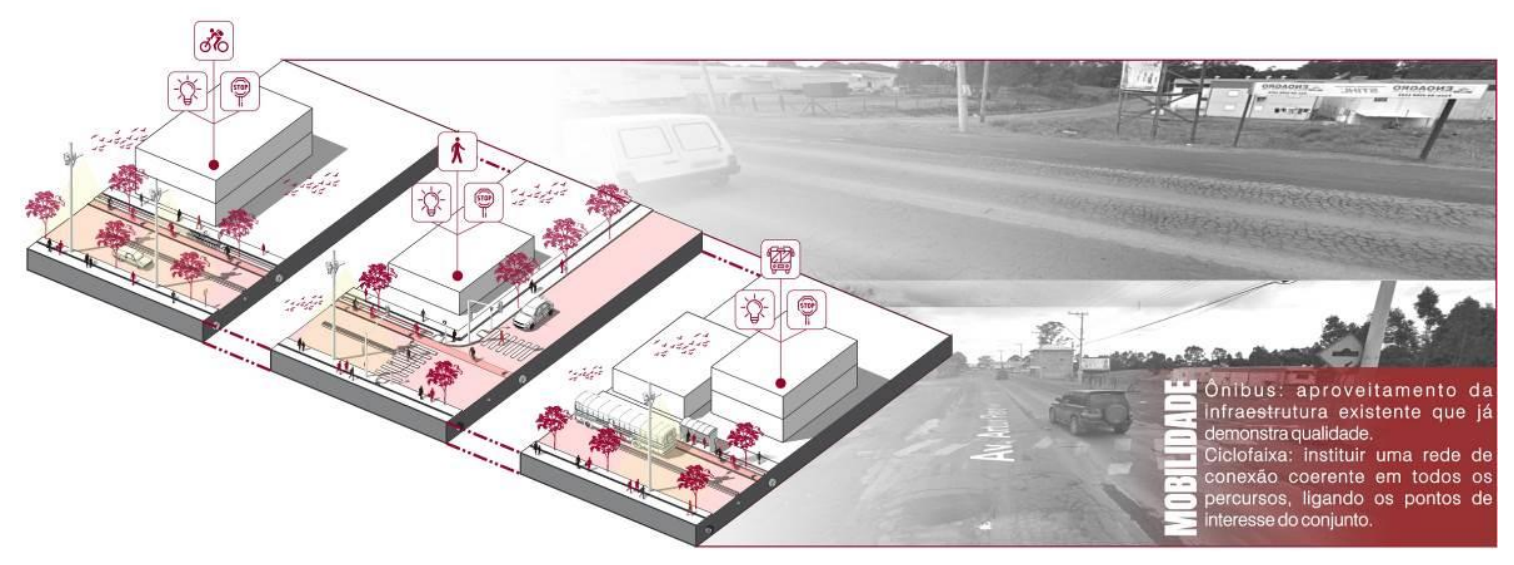

Figura 15 - Estratégias de mobilidade urbana -

Fonte: Autoras (2018) 
Mesmo assim, vias do centro de Forqueta ainda estão conformadas para os veículos, e os pedestres perderam seu espaço e a relação com a rua se tornou cada vez mais distante, trazendo como consequência o desuso dos espaços aberto e pôr fim a sua falta de manutenção e apropriação por parte da comunidade. Essa falta de interesse pelo espaço da rua surge quando os usuários não se sentem mais "donos" daqueles locais, e com isso não os utilizam nem os mantem de forma qualificada, o que gera ainda mais insegurança para os espaços urbanos.

As qualificações propostas voltam a privilegiar o pedestre e as suas mais variadas formas de recuperar a vivência na rua, com isso a ciclovia existente, recebe requalificação e sinalização, junto com a melhoria nos passeios públicos e acessos para as pessoas. O veículo particular passa a ser um elemento secundário, e são propostas melhorias no transporte coletivo com a implantação do VLT (veículo leve sobre trilhos), já instituído pelo Plano de Revitalização das Ferrovias do Governo Federal e viabilizados pelo comitê técnico da Aglomeração do Nordeste - AUNe.

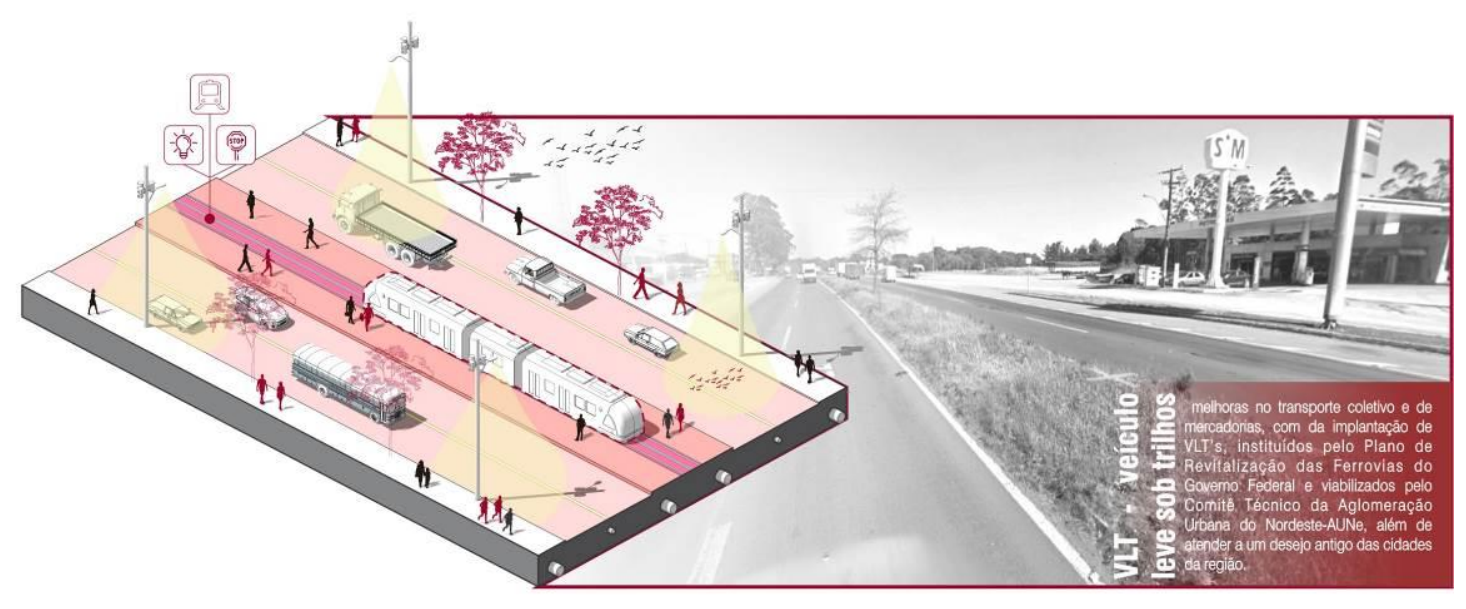

Figura 16 - Proposta de transporte coletivo alternativo (VLT) -

Fonte: Autoras (2018)

Além de melhorias no transporte, vem a requalificação do acesso ao centro de Forqueta, que se dá pela RS-122, resgatando essa conexão e atraindo quem passa a conhecer a localidade através do seu potencial cultural e comercial através da produção de uva e vinho. Para que isso aconteça é necessário que haja a diminuição de velocidade nesse trecho, e de uma entrada secundária que conduza ao centro do distrito, o que estimulará a sociabilidade dos pedestres com a rua e com a rodovia.

\subsection{Implantação}

As propostas de intervenção feitas para o distrito de Forqueta, apresentadas nesse artigo, tem por objetivo seu crescimento e desenvolvimento de uma forma sustentável. As soluções estão associadas para construir um espaço em que as pessoas sejam estimuladas a explorar e vivenciar a rua como espaço urbano de interpelações e experiências, e que com isso criem um sentimento de pertencimento com o bairro. "A maioria identifica-se com um lugar da cidade porque o utiliza e passa a conhece-lo quase intimamente". (JACOBS, 2000, p.141). 
Com a viabilidade de mobilidade, novos atrativos turísticos e a possibilidade de criar um espaço com mais qualidade e permanência para os usuários, a proposta beneficia Forqueta e evidencia a vocação do lugar, divulgando a sua identidade e cultura da região, com o espaço da rua funcionando de forma efetiva.

Além disso, para atender a questão da viabilidade técnica e sustentável da proposta, foram articuladas prospecções da implantação do projeto urbanístico, levando em consideração a seguinte cronologia:

- 10 anos, 1 a fase: infraestrutura para receber o projeto, estabelecer uma relação de segurança entre os moradores e os usuários do espaço, execução de calçadas, iluminação pública, sinalização, vegetação e mobiliário urbano adequado. Prospecta-se que nesse período a utilização do espaço comece a atender as demandas do local, potencializando a vitalidade da área central e incentivando novas práticas sociais e culturais.

- 20 anos, 2 a fase: com o espaço já sendo utilizado mais ativamente e com o reconhecimento e apoio da população local para o convívio e divulgação do espaço, nessa fase são iniciados os reusos das edificações que foram marcadas como históricas para o centro de Forqueta. Essas intervenções intensificam a identidade da comunidade e a infraestrutura para receber turistas é aprimorada, com isso a economia ganha força e os produtos locais são reconhecidos e auxiliam a impulsionar o desenvolvimento do distrito.

- 50 anos, 3afase: com a implementação completa do roteiro do Vale do Trentino, o foco turístico e de atrativo se expande do centro e passa a valorizar e mostrar a produção local e o percurso que pode ser feito, tanto com transporte alternativo, como bicicletas, quanto por veículos de passeio. As paisagens culturais e naturais ajudam a valorizar Forqueta e junto com isso um crescimento econômico efetivo, juntando os equipamentos urbanos do centro e conectando-os as vinícolas locais.

Essa lógica de proposta mostra que é possível iniciar as intervenções de forma mais sutis, e com isso ter o apoio e a apropriação adequada da comunidade, para que esta também faça a sua parte em preservar e qualificar ainda mais o projeto. Logo, as implementações começam a atrair um novo público, o que possibilita que se tenha investimentos para a execução e continuidade da implantação. Sustentabilidade é a ordem para que o sistema se mantenha sozinho e que a população local se envolva na divulgação, criação de atividades e retroalimentação do projeto, com eventos que potencializem o caráter peculiar de Forqueta.

\section{CONSIDERAÇÕES FINAIS}

A proposta demonstra que o urbanismo quando bem trabalhado pode revelar o potencial latente, especialmente em localidades ou cidades pequenas com pouco investimento.

Boas intervenções muitas vezes partem de ideias simples e de lugares que já são muito ricos, porém pouco explorados. Pode-se pensar que "[...] quase ninguém vai espontaneamente de um lugar sem atrativos para outro, idêntico, 
mesmo que o esforço físico seja pequeno" (JACOBS, 2000, p.142). Forqueta é um desses lugares cheios de espaços a serem descobertos e com um potencial cultural muito forte, mantido pelo espírito de comunidade local. A proposta só conseguiu evidenciar e transformar isso em um projeto de intervenção urbana, que costura o existente e as prospecções para um futuro.

A estruturação do projeto em três etapas de implantação busca o desenvolvimento do distrito de maneira sustentável e priorizando as atividades sociais, culturais e habituais da localidade, com o objetivo de atrair novos turistas e com isso qualificar a economia.

Como proposta de desenho urbano as estratégias projetuais foram pensadas e desenvolvidas ao nível do observador, que é onde os usuários vivenciam os espaços. Essa é uma das grandes destrezas do urbano, porque muitas vezes belos projetos não são compreendidos, impossibilitando as pessoas se sintam parte deles, e quando não há a apropriação pela comunidade não existe urbanismo de qualidade.

\section{REFERÊNCIAS}

BAKER, G. Análisis de la Forma: urbanismo y arquitectura. Barcelona: G. Gili, 1991.

INSTITUTO BRASILEIRO DE GEOGRAFIA E ESTATÍSTICA (IBGE). Disponível em: <http://WwW.ibge.gov.br>.

JACOBS, J. Morte e vida de grandes cidades. São Paulo: Martins Fontes. 2000.

LYNCH, K. A Imagem da Cidade. 3. ed. Tradução de por Jefferson Luiz Camargo. São Paulo: Martins Fontes, 2011.

Forqueta: A memória dos esquecidos. Revista PROJETO. São Paulo: ed 446. 1977 - mensal.

VICTUR. Valorização do turismo integrado à identificação dos territórios. João Wianey Tonus (org). Caxias do Sul: Belas-Letras, 2007. 